\title{
Comparison of hydroxyethylstarch 130/0.4 and ringer's lactate on fibrinogen level in cesarean operations: a randomized clinical trial
}

\author{
๑Dihan Aydın Güzey, @Havva Esra Uyar Türkyılmaz \\ Ankara City Hospital, Department of Anesthesiology and Reanimation, Ankara, Turkey
}

Cite this article as: Aydın Güzey N, Uyar Türkyılmaz HE. Comparison of hydroxyethylstarch 130/0.4 and ringer's lactate on fibrinogen level in cesarean operations: a randomized clinical trial. J Health Sci Med 2021; 4(2): 166-169.

\begin{abstract}
Aim: Colloids are effective in volume resuscitation but they have been shown to have negative impacts on fibrin formation. The aim of this study is to evaluate the effect of using low dose HES solutions on fibrinogen level in cesarean operations.

Material and Method: 100 women, scheduled for cesarean surgery with spinal anesthesia were enrolled in the study. Patients were assigned to receive hydroxyethyl starch (HES) 130/0.4 in addition to a basic infusion of Ringer's lactate (RL) solution (GROUP HES) or exclusively RL solution throughout the intraoperative study period (GROUP RL). Patients in the Group HES received HES 130/0.4 $8 \mathrm{ml} . \mathrm{kg}^{-1} \mathrm{~h}^{-1}$ with RL solution $5 \mathrm{~mL} \cdot \mathrm{kg}^{-1} \cdot \mathrm{h}^{-1}$ and Group RL received RL solution $20 \mathrm{~mL} \mathrm{~kg}{ }^{-1} \cdot \mathrm{h}^{-1}$. Fibrinogen, haemoglobin, platelet values were recorded preoperatively and at postoperative first hour.

Results: HES 130/0.4 was used only in Group HES, amount consumed was $418 \pm 90 \mathrm{~mL}$. Ringer's lactate consumption was $276 \pm 58 \mathrm{~mL}$ for Group HES and $1197 \pm 197 \mathrm{~mL}$ for Group RL. There was a significant change in haemoglobin and fibrinogen values before and after surgery between groups. The mean decrease in fibrinogen was $92.18 \pm 60.12 \mathrm{mg} / \mathrm{dL}$ in Group HES and $65.70 \pm 83.61 \mathrm{mg} / \mathrm{dL}$ in Group RL.

Conclusion: HES 130/0.4 solution can be used in elective cesarean operations without predicted or active hemorrhage. When there is a hemorrhage of any reason in HES 130/0.4 used cases, the decrease in fibrinogen level must be anticipated and rapid replacement of fibrinogen must be kept in mind.
\end{abstract}

Keywords: Fibrinogen, hydroxyethyl starch, cesarean operations

\section{INTRODUCTION}

Colloids are more effective in volume resuscitation than the cristalloids based on their longer duration in intravascular area and higher volume effect, Recent studies showed that, colloids have negative impacts on fibrin formation. Especially when administered in high doses ( $>50 \mathrm{ml} . \mathrm{kg} \cdot \mathrm{d}^{-1}$ or $>1.5$ liters) or in patients who has prior coagulation problems; they had been shown to cause more haemodilution and have serious adverse effects $(1,2)$.

Low doses of hydroxyethyl starch (HES) 130/0.4 solutions are frequently used at perioperative period to prevent hypotension and related complications. In case of unexpected hemorrhage, the coagulation defect related to the use of HES 130/0.4 solutions may enhance blood loss. The aim of this study is to evaluate the effect of using low dose HES solutions on fibrinogen level in noncomplicated cesarean operations and guide intraoperative fluid management in accordance with this information.

\section{MATERIAL AND METHOD}

The study was carried out with the permission of Zekai Tahir Burak Women's Health Training and Research Hospital's institutional review board (2011-KAEK-19, Approval code: 41/2018).

After Ethics Committee approval, one hundred pregnant women, ASA I or II, scheduled for cesarean surgery with spinal anesthesia were enrolled in the study. An informed written consent was taken from the patients before participation. Exclusion criteria were; refusal or contraindication for regional anaesthesia; age under 18 or over 40 years; body weight over $100 \mathrm{~kg}$ and body height below $150 \mathrm{~cm}$; pregnancy with gestational age under 36 weeks and multiple gestations, fetal anomaly, placental invasion anomalies; history of preeclampsia/eclampsia, abnormal values of fibrinogen, coagulation tests and haemoglobin, haematocrit and platelet. 
Using a computer-generated randomization list, patients were assigned to receive medium molecularweight medium-substituted hydroxyethyl starch (6\% Voluven ${ }^{\circledast} 130 / 0.4$, Fresenius, Pharma Austria $\mathrm{GmbH}, \mathrm{Graz}$, Austria) in addition to a basic infusion of Ringer's lactate solution (Ringer Laktat ${ }^{\oplus}$, Osel İlaç Sanayi, İstanbul, Turkey) (GROUP HES) or exclusively Ringer's lactate solution throughout the intraoperative study period (GROUP RL). Patients in the Group HES received hydroxyethyl starch $130 / 0.48 \mathrm{~mL} \cdot \mathrm{kg}^{-1} \mathrm{~h}^{-1}$ with Ringer lactate solution $5 \mathrm{~mL} \cdot \mathrm{kg}^{-1} \cdot \mathrm{h}^{-1}$ and Group RL received only Ringer lactate solution $20 \mathrm{~mL} \mathrm{~kg}{ }^{-1} \cdot \mathrm{h}^{-1}$. The local pharmacy prepared the study solutions that were supplied in identical $500 \mathrm{ml}$ bottles. An IV line was established and flushed with the randomized fluid placed in an opaque bag to blind the outcome assessor, who recorded the volume of lost blood by suction and weight of swabs.

The volume regimen was based on the presumption that hydroxyethyl starch and Ringer lactate solution show different volume effects. Fluids were actively warmed with fluid warmer to $41^{\circ} \mathrm{C}$. The safety of usage and stability of HES that had been warmed has been shown $(3,4)$.

Preoperative fibrinogen, haemoglobin, and platelet values were recorded.

With patients in the sitting position, spinal anaesthesia was performed with 26 gauge atraucan (atrau-com ${ }^{\circledast}$, egemen INTERNATIONAL, İzmir) needle. A standart solution of $10 \mathrm{mg}$ hyperbaric bupivacaine was injected in 30 seconds to cerebrospinal fluid. After the procedure, the patients lied supine with $20^{\circ}$ tilt to left to prevent hypotension caused by aorta-caval pressure.

Hypotension was defined as a decrease of $20 \%$ or more below baseline mean arterial pressure value and treatment was made with ephedrine bolus of $10 \mathrm{mg}$ until the mean arterial pressure returned to normal values. Bradycardia was defined as heart rate $<50$ beats. $\min ^{-1}$ and treatment was made with atropine.

After taking the patients to recovery room, infusion of HES 130/0.4 was terminated and fluid infusion continued with Ringer's lactate in both groups. Patients who were given more than $1500 \mathrm{~mL}$ HES 130/0.4 were excluded from the analysis. Patients who had bleeding during/after operation; given any blood product, tranexamic acid or fibrinogen or given oxytocin more than routine practice were also excluded from the analysis.

Blood loss during the operation was recorded. Patients were excluded from the analysis if blood loss was more than $1000 \mathrm{~mL}$. Fibrinogen, haemoglobin, platelet values were recorded at postoperative first hour.
Statistical analysies were performed using SPSS Software (Version 21.0, SPSS Inc., IL, USA). The sample size of study was calculated based on the sample size of previous studies, using a significance level of $5 \%(\mathrm{p}=0.05)$ and power of $97.5 \%$ Categorical data are expresses as counts and percentages (\%) and continuous data as mean \pm SD (range). After determining normal distrubution using Kolmogorov-Smirnov test for quantitative data, analysis were performed using Student's t-test or Mann-Whitney U-test. $\chi^{2}$ test was used for qualitative data. $\mathrm{p}<0.05$ was considered significant.

\section{RESULTS}

The data of one hundred patients, consisting of fifty patients from each group were analysed. Hydroxyethyl starch 130/0.4 was used only in Group HES, amount of voluven consumed was $41 \pm 90 \mathrm{~mL}$. Mean Ringer's lactate consumption was $276 \pm 58 \mathrm{~mL}$ for Group HES and $1197 \pm 197 \mathrm{~mL}$ for Group RL.

Patients' characteristics, duration of surgery and blood loss in surgery are shown in Table 1. Body weight, body height, duration of surgery and blood loss did not differ among groups, with the only exception that mean age was higher in Group RL as compared with group HES. This difference was statistically significant $(p=0.02)$ but without clinical relevance.

\begin{tabular}{|c|c|c|c|}
\hline & $\begin{array}{c}\text { Group HES } \\
\text { mean } \pm \text { SD }\end{array}$ & $\begin{array}{l}\text { Group RL } \\
\text { mean } \pm S D\end{array}$ & $\mathbf{p}$ \\
\hline Weight (kg) & $73.3 \pm 8.1$ & $75.6 \pm 9.6$ & 0.320 \\
\hline Height (cm) & $159.9 \pm 5.6$ & $160.4 \pm 5.4$ & 0.495 \\
\hline Age (years) & $27.7 \pm 5.4$ & $30.1 \pm 4.8$ & $0.02^{*}$ \\
\hline Blood loss (mL) & $596.8 \pm 203.4$ & $618 \pm 198.6$ & 0.275 \\
\hline $\begin{array}{l}\text { Duration of } \\
\text { surgery (min) }\end{array}$ & $43.9 \pm 7.3$ & $45.3 \pm 6.8$ & 0.162 \\
\hline
\end{tabular}

As shown in Table 2, the distribution of operation indications did not differ among groups $(\mathrm{p}=0.568)$.

\begin{tabular}{|lcc|}
\hline \multicolumn{3}{|c|}{ Table 2. cesarean indication of the study participants } \\
\hline & $\begin{array}{c}\text { Group HES } \\
\text { N (\%) }\end{array}$ & $\begin{array}{c}\text { Group RL } \\
\text { N (\%) }\end{array}$ \\
\hline Fetal distress & $4(8 \%)$ & $5(10 \%)$ \\
Cephalopelvic disproportion & $7(14 \%)$ & $3(6 \%)$ \\
Previous uterin surgery & $32(64 \%)$ & $36(72 \%)$ \\
Abnormal presentation & $7(14 \%)$ & $6(12 \%)$ \\
Total & $50(100 \%)$ & $50(100 \%)$ \\
\hline
\end{tabular}

The change in haemoglobin values before and after surgery was statistically significantly different among groups $(\mathrm{p}=0.05)$. Preoperative and postoperative change in platelet values did not differ among groups ( $\mathrm{p}=0.08)$ (Table 3 ). 


\begin{tabular}{|c|c|c|c|}
\hline & $\begin{array}{c}\text { Group HES } \\
\text { Mean }( \pm S D)\end{array}$ & $\begin{array}{c}\text { Group RL } \\
\operatorname{Mean}( \pm \text { SD })\end{array}$ & p \\
\hline $\begin{array}{l}\text { Change in } \\
\text { haemoglobin } \\
\text { value (g/dl) }\end{array}$ & $1.24( \pm 0.71) \downarrow \downarrow$ & $0.69( \pm 0.66) \downarrow \downarrow$ & $0.00^{*}$ \\
\hline $\begin{array}{l}\text { Change in } \\
\text { platelet value (n) }\end{array}$ & $28380( \pm 26949) \downarrow \downarrow$ & $24195( \pm 38742) \downarrow \downarrow$ & 0.08 \\
\hline $\begin{array}{l}\text { Change in } \\
\text { fibrinogen value } \\
(\mathrm{mg} / \mathrm{dl})\end{array}$ & $92.18( \pm 60.12) \downarrow \downarrow$ & $65.70( \pm 83.61) \downarrow \downarrow$ & $0.004 *$ \\
\hline${ }^{*} \mathrm{p}<0.05$ & & & \\
\hline
\end{tabular}

There was a statistically significant change in fibrinogen value before and after surgery between Group HES and Group RL. As shown in Table 3, the mean decrease in fibrinogen value was $92.18 \pm 60.12 \mathrm{mg} / \mathrm{dL}$ in Group HES and $65.70 \pm 83.61 \mathrm{mg} / \mathrm{dL}$ in Group RL.

Number of patients with a fibrinogen level below 200 $\mathrm{mg} / \mathrm{dL}$ did not differ among groups ( $\mathrm{p}=0.24)$ (Table 4).

\begin{tabular}{|c|c|c|c|}
\hline & $\begin{array}{c}\text { Fibrinogen >200 } \\
\text { mg/dl N (\%) }\end{array}$ & $\begin{array}{c}\text { Fibrinogen }<200 \\
\text { mg/dl N (\%) }\end{array}$ & Total \\
\hline Group HES & $50(100 \%)$ & $0(0 \%)$ & $50(100 \%)$ \\
\hline Group RL & 47 (94\%) & $3(6 \%)$ & $50(100 \%)$ \\
\hline
\end{tabular}

\section{DISCUSSION}

Hydroxyethyl starch 130/0.4 solution is shown to be more effective than cristalloids in maintaining systolic and diastolic blood pressure, regulating changes in heart rate, ephedrine use and total amount of infused solution (5). Their use especially in cesarean section with spinal anaesthesia has many benefits in controlling the blood pressure of the patient and helps preventing the effects of hypotension on mother and fetus.

Fibrinogen level is found to be the main determinant of coagulopathy in postpartum hemorrhage (6) and postoperative bleeding in cardiac surgery (7). Although HES solutions are more effective than Ringer's lactate solution in volume resuscitation, the most remarkable effect of HES is reported to be a decrease in fibrinogen level and impairment in fibrin polymerisation $(8,9)$. The impairment in total cloth strength when colloids were used is reported to be with a decrease in the fibrinogen component of the cloth; furthermore with both HES $200 / 0.5$ and $4 \%$ modified gelatin a more decrease in fibrinogen concentration is observed (10).

Maximum clot firmness (MCF) is known to be associated with function and level of platelets and fibrinogen level (11). Fenger and colleagues demonstrated that hemodulition with HES solutions leads to a decrement in MCF and a coagulopathy with unchanged clotting time, maximum velocity and time to maximum velocity (9). It is reported in a study that colloids affect the speed and quality of clot formation by interacting with functional measured polimerisation of fibrinogen/fibrin and fibrinogen concentration; as a result although coagulation factors and coagulation time remain unchanged, results of functional measured fibrinogen/fibrin polymerisation tests become impaired (12).

Based on the long half-life of HES solutions; ending the infusion of HES solution does not resolve coagulopathy in a short duration of time (13). The insufficiency of fibrinogen is reported to occur when colloids and red blood cell components are used for compansation of blood loss during major urologic or abdominal surgery In this study, fibrinogen concentrations reported to decrease in the colloid groups by average $100 \mathrm{mg} / \mathrm{dl}$ throughout the observation period (14). This shows that severely decreased fibrinogen concentrations might be reached earlier than expected time.

In our study, there was a significant reduction with HES 130/0.4 when compared with Ringer's lactate solution in fibrinogen values although average amount of used HES 130/0.4 was $418 \mathrm{ml}$-considering the fact that the clinical coagulopathic effects of HES 130/0.4 are mostly seen when large volume $(>1.5 \mathrm{~L})$ of colloids have been infused.

Intraoperative and postoperative major bleeding did not occur in any of the patients. The patients with a blood loss of more than $1000 \mathrm{~mL}$ would be excluded from the study but none of the patients exceeded this limit. The change in haemoglobin values before and after surgery was statistically significantly different among groups. The reduction in haemoglobin value in group HES is greater than the reduction in haemoglobin value in group RL. The reduction in haemoglobin value can be explained either by the negative impact of HES 130/0.4 on blood coagulation or by the more profound haemodiluting effect; but in any case it leads to a quicker reach to red blood cell transfusion tresholds.

When a cesarean section without expectable bleeding is anticipated in preoperative evaluation, HES 130/0.4 solution can be used to prevent hypotension related to spinal anaesthesia. Considering that fibrinogen concentrations below $200 \mathrm{mg} / \mathrm{dL}$ is found to be predictive for serious postopartum hemorrhage (6), it would be useful to determine preoperative fibrinogen level in regulating intraoperative fluid regimen.

One limitation of our study seems to be the lack of viscoelastic tests as standard laboratory tests are not able to evaluate the platelet interactions with the endothelium, erythrocytes and fibrinogen but as the main purpose of our study is focus on the final fibrinogen level to evaluate the effect of using low dose HES solutions, performing viscoelastic tests is not considered necessary. 


\section{CONCLUSION}

Hydroxyethyl starch 130/0.4 solution can be used in elective cesarean operations without predicted or active hemorrhage. According to the results of our study, although it causes a significant reduction in fibrinogen level when compared with Ringer's Lactat solution, this situation does not lead to an consequential clinical outcome in patients. In consideration of above-mentioned studies, when there is a hemorrhage of any reason in HES $130 / 0.4$ used cases, the decrease in fibrinogen level must be anticipated and rapid replacement of fibrinogen must be kept in mind.

\section{ETHICAL DECLARATIONS}

Ethics Committee Approval: The study was received from the institutional review board (Zekai Tahir Burak Women's Health Training and Research Hospital Institutional Review Board (2011-KAEK-2019, approval code: 41/2018).

Informed Consent: Written informed consent form was obtained from patients.

Referee Evaluation Process: Externally peer-reviewed.

Conflict of Interest Statement: The authors have no conflicts of interest to declare.

Financial Disclosure: The authors declared that this study has received no financial support.

Author Contributions: All of the authors declare that they have all participated in the design, execution, and analysis of the paper, and that they have approved the final version.

\section{REFERENCES}

1. Skhirtladze K, Base EM, Lassnigg A, et al. Comparison of the effects of albumin 5\%, hydroxyethyl starch 130/0.4 6\%, and Ringer's lactate on blood loss and coagulation after cardiac surgery. Br J Anaesth 2014; 112: 255-64.

2. Levi M, Jonge Ed. Clinical relevance of the effects of plasma expanders on coagulation. Semin Thromb Hemost 2007; 33: 810-5.

3. Yamakage M, Sasaki H, Jeong SW, Iwasaki S, Namiki A. Safety and beneficial effect on body core temperature of a prewarmed plasma substitute--hydroxyethyl starch--during anesthesia. J Anesth 2004; 18: 166-71.

4. Yokoyama K, Suzuki M, Shimada Y, Matsushima T, Bito H, Sakamoto A. Effect of administration of pre-warmed intravenous fluids on the frequency of hypothermia following spinal anesthesia for cesarean delivery. J Clin Anesth 2009; 21: 242-8.

5. Gousheh MR, Akhondzade R, Asl Aghahoseini H, Olapour A, Rashidi M. The effects of pre-spinal anesthesia administration of crystalloid and colloid solutions on hypotension in elective cesarean section. Anesth Pain Med 2018; 8: e69446.

6. Charbit B, Mandelbrot L, Samain E, et al. The decrease of fibrinogen is an early predictor of the severity of postpartum hemorrhage. J Thromb Haemost 2007; 5: 266-73.
7. Karlsson M, Ternström L, Hyllner M, Baghaei F, Nilsson S, Jeppsson A. Plasma fibrinogen level, bleeding, and transfusion after on-pump coronary artery bypass grafting surgery: a prospective observational study. Transfusion 2008; 48: 2152-8

8. Krzych ŁJ, Czempik PF. Hooves better than potatoes: in vitro effects of balanced crystalloid and colloids on functional parameters of coagulation and fibrinolysis. Pol Arch Intern Med 2017; 127: 209-11.

9. Fenger-Eriksen C, Tønnesen E, Ingerslev J, Sørensen B. Mechanisms of hydroxyethyl starch-induced dilutional coagulopathy. J Thromb Haemost 2009; 7: 1099-105.

10.Innerhofer P, Fries D, Margreiter J, et al. The effects of perioperatively administered colloids and crystalloids on primary platelet-mediated hemostasis and clot formation. Anesth Analg 2002; 95: 858-65.

11. Oshita K, Az-ma T, Osawa Y, Yuge O. Quantitative measurement of thromboelastography as a function of platelet count. Anesth Analg 1999; 89: 296-9.

12. Mittermayr M, Streif W, Haas T, et al. Hemostatic changes after crystalloid or colloid fluid administration during major orthopedic surgery: the role of fibrinogen administration. Anesth Analg 2007; 105: 905-17

13. Barron ME, Wilkes MM, Navickis RJ. A systematic review of the comparative safety of colloids. Arch Surg 2004; 139: 552-63.

14. Hiippala ST, Myllylä GJ, Vahtera EM. Hemostatic factors and replacement of major blood loss with plasma-poor red cell concentrates. Anesth Analg 1995; 81: 360-5. 